\title{
RAPID IMMOBILISATION OF 8-HYDROXYQUINOLINE ONTO SILICA MATERIALS AND ITS APPLICATION FOR ON-LINE SOLID-PHASE EXTRACTION OF TRANSITION METALS FROM ENVIRONMENTAL SAMPLES BEFORE ICP-OES DETERMINATION
}

\author{
A.O. ALSUHAIMI ${ }^{1, *}$ \\ T. MCCREADY ${ }^{2}$
}

Received: 02/10/11

Accepted: 06/02/12

\author{
${ }^{1}$ Chemistry Department, Faculty of Science, \\ Taibah University P O. Box 30002 Prince Naïf Road, \\ AlMadinah AlMunawarah Saudi Arabia \\ ${ }^{2}$ Chemistry Department, The University of Hull, \\ Cottingham Road, Kingston upon Hull, \\ HU6 7RX, UK \\ *to whom all correspondence should be addressed: \\ e-mail: asuhaimi@taibahu.edu.sa
}

\begin{abstract}
Chelating resins based on immobilised oxines are attractive solid-phase extraction (SPE) materials in the analysis of trace metals from environmental samples. The most common immobilisation procedure for bonding oxines to silica supports is time-consuming and incompatible with "green chemistry" regulations. In this work, a rapid, environmentally friendly chemical transformation to attach oxines (i.e. 8-hydroxyquinoline) to silica surfaces is reported. The chelating resin produced by the procedure described here maintains the chemical configuration (including the spacer arm separating the reactive groups from the matrix) and is identical to that obtained with the traditional method. The resin showed satisfactory capacity exchange and excellent performance as a SPE material for on-line sample preparation (preconcentration and matrix elimination) of some transition metals before their determination by ICP-OES. The applicability of this SPE material was tested by analysing $\mathrm{Cu}, \mathrm{Co}, \mathrm{Zn}, \mathrm{Ni}$ and $\mathrm{Pb}$ in the range of $50-300 \mathrm{ng} \mathrm{ml}^{-1}$ from a synthetic matrix simulating sediment. The recovery values ranged from $100 \%$ for $\mathrm{Zn}$ to $70 \%$ for $\mathrm{Ni}$. The system was used with optimised parameters to analyse these ions in different sediment reference materials. The results showed good agreement with certified values.
\end{abstract}

KEYWORDS: Environmentally friendly, immobilisation, online SPE, ICP-OES, 8-hydroxyquinoline, transition elements, environmental samples.

\section{INTRODUCTION}

During the last twenty years, solid-phase extraction (SPE) has established itself as a replacement for the traditional technique to perform analyte preconcentration and matrix elimination in the analysis of trace metals from difficult matrices such as environmental samples. In practice, SPE for metal ions is usually carried out with one of two processes. In the first approach, metal ions are allowed to react with specific chelating agents, either in a batch or in a flowing stream, to form a metal-chelator complex, which is subsequently captured on appropriate solid materials, such as C18 (Ghanthai et al., 2011), Amberlite XAD (Soylak et al., 2003), activated carbon (Mikula and Puzio, 2007), coated alumina (Hiraide et al., 1997) and PTFE knotted reactors (Anthemidis et al., 2001). In the other approach, chelating reagents are attached to suitable solid materials, and metal ions are trapped as complexes on the immobilised chelating agent (chelating resin). The reagent can be attached either by physical impregnation or by covalent bonding. Chemical bonding of a chelating reagent with the desired functionality offers a unique advantage, since detachment of the grafted agent is prevented by the strong covalent bonding of the molecule to the substrate. Therefore, an immobilised reagent can be re-used many times (Rao and Gladis, 2001; 2002). 
Oxine and its derivatives are among the first chelating reagents to be successfully immobilised to synthesis chelating resins. Chemical attachment of these reagents to a variety of supports has been the subject of many studies. Naturally occurring polymers (e.g. celloluse), organic polymers and inorganic polymers (e.g. silica) are popular; other materials such as activated carbon (Tian et al., 2008) and bentonite calys (Ozcan et al., 2009) are also used. Some examples of the application of these supports and the chemical transformations most widely used in the synthesis of oxine-based resins are described below. Most of the reported transformations involve initial surface activation with an amino group.

Bauman et al. (1967) described a procedure for diazo coupling of hydroxyquinoline and dithizone to benzidine carboxymethylcellulose to recover trace metals from seawater. Other workers (Csanay et al., 1989) coupled 8-hydroxyquinoline-5-sulphonic acid (sulphoxine) to cellulose by converting carboxymethylcellulose into aminocellulose followed by a Mannich reaction with formaldehyde. A similar procedure was used for covalent attachment of sulphoxine to chlorodeoxy- and ethylenediamine-cellulose. (Zih-Perenyi et al., 1998). 8-Hydroxyquinoline (8-HQ) immobilised onto polystyrene-divinyl benzene (DVB) was synthesised and investigated by many workers (Vernon at. al., 1973; Vernon at al., 1977; Parirish 1982). Other vinyl polymer materials (e.g., Fractogel TSK) have also been used (Landing et al., 1988; Admas and Powell 2001). The synthesis process involves an attachment of nitrobenzoyl groups, followed by reduction of the nitro group, which was then diazotized to allow oxines coupling. Another route for the addition of nitro groups is the direct nitration of the phenyl ring using a mixture of concentrated nitric and sulphuric acids (Jain et al., 1997). A novel simplified procedure for producing 8-HQ covalently bonded to a vinylpolymer agglomerate resin via an amino link between the resin and the $8-\mathrm{HQ}$ functional group was described by Landing and co-workers (Dierssen et al., 2001). This linkage was reported to be more stable to acid or base hydrolysis than the ester linkage employed in their original method, (Landing et al. 1988 ) and greatly reduce the bleeding of the $8-\mathrm{HQ}$ functional groups from the resin. The new resin was used to extract trace metals from natural water. Recently, 8-HQ has been successfully immobilised onto polyacrylonitrile (PAN) hollow fibre membrane and used to preconcentrate rare earth elements (REEs) metals from seawater prior to their detection using ICP-MS. The immobilisation involved two steps. Firstly, PAN was reacted with hydrazine at $90-94{ }^{\circ} \mathrm{C}$, and then 8$\mathrm{HQ}$ was coupled via diazotization (Wen et al., 1999). Reagents were immobilised onto cellulose and polymeric supports, although they exhibited an acceptable exchange capacity and capability to extract metal from solutions over a definite $\mathrm{pH}$ range. However, it has been proven that these materials suffer from many serious limitations, such as slow kinetic exchange, swelling and shrinking, and lack of mechanical stability in dynamic systems. Cellulose and its derivatives have the additional problem of degradation due to microbial action.

Silica gel and glass materials are known to be almost free from the above limitations. In addition they have a reactive surface that can be activated easily. Most frequently, the surface activation prior to the attachment of oxins is carried out using amino silane. Several chemical transformations have been used to achieve the attachment of oxins on the amenated silica, including; (1) Mannich reaction via condensation with formaldehyde (Lan and Yang, 1994; Tertykh et al., 2000; Zheng et al., 2006), (2) the formation of Schiff's base by reacting a reactive derivative such as 5-formyl-8hydroxyquinoline with the aminated silica (Goswami, 2003), and (3) coupling of oxins to the aminated silica surface via diazoniation.

Essentially, most of the reported procedures for covalent attachment of oxines onto aminated silica surfaces have been achieved using diazo coupling following a transformation procedure firstly developed by Hill for enzyme immobilisation (Hill, 1973). In this procedure, the silica surface is aminated via its silylation with aminoalkylsilane, generally 3-aminopropyltriethoxysilane. The resulting aminoalkylated silica is reacted with $p$-nitrobenzoylchloride, and then the nitro group is reduced to give a $p$-aminobenzoyl derivative. This intermediate is then diazotized to the diazonioum derivative, and finally coupled with oxines. This procedure, however, suffers from being too long as it involves many preparation steps and is more likely to generate hazardous wastes. Thus, it does not fulfil the new requirement of green chemistry (Prado, 2002). For instance, during the benzoylation step, the substrate is heated for several hours in chloroform. Marshall and Mottola (Marshall and Mottola 1983) have used an aminophenyl silane '(aminophenyl)triethoxysilane' to activate the silica surface, which is then diazotised to facilitate oxine coupling in one step, thus significantly simplifed and shortened the immobilisation procedure; however, steric hindrance effect is more likely to 
distress resin functionality as the short linkage is not sufficient to distant the functional group away from the solid support.

In this work, the silylation reagent, $p$-aminophenoxypropyltrimethylsilane, was considered as a good candidate for the preparation of transitional aminated silica. The presence of phenoxypropyl chain reduces steric effect at the support, allowing more chelating groups to be available away from the silica surface for reaction with metal ions. In addition, the final product has a chemical structure and stable linkage identical to that synthesised according to the most common immobilisation procedure.

\section{EXPERIMENTAL WORK}

\subsection{Chemical reagents}

All reagents used in the immobilisation or analytical process were of analytical grade. The solid support controlled porous glass (CPG) (mesh size 120-200) and sodium nitrite $\left(\mathrm{NaNO}_{2}\right)$ were purchased from Sigma (Poole, UK). The silylation reagent ( $p$-aminophenoxypropyl)trimethoxysilanae was obtained from ABCR (Manchester, UK), anhydrous toluene and ethanol from Fisher Scientific (UK), hydrochloric acid from Philip Harris, UK, and super purity nitric acid from Romil (Cambridge, UK). Elemental stock solutions (1000 $\mathrm{g} \mathrm{m}^{-1}$, SpectrosoL, Merck, Poole, Dorset, UK) were used in the preparation of standard solutions of the studied metals. Ammonium acetate buffer was prepared from the solid and purified by passing through a column of Chelex-100 (BioRad, Hemel Hempstead, UK). The $\mathrm{pH}$ was adjusted to the required value with acetic acid or liquid ammonia. The masking agent pyrophosphoric acid (Sigma Aldrich) was added to the buffer immediately prior to the analysis procedure. High purity water (18 $\Omega \mathrm{cm}$ resistivity, Elgastat UHQ PS, High Wycombe, UK) was used throughout.

All glassware were thoroughly cleaned with Lipsol detergent (LIP, Shipley, UK) and soaked overnight in $5 \% \mathrm{HNO}_{3}$. Immediately before use, all acid soaked glasses were rinsed with high purity water.

\subsection{Instrumentations}

Elemental analysis was performed with a CHN Fisons Instrument EA1108 (CE Instruments Ltd., UK). The ICP-OES system used consisted of Perkin-Elmer Plasma 40 Inductively Coupled Plasma Optical Emission Spectrometer (ICP-OES) (Perkin Elmer, Beaconsfield, Buckinghamshire, UK) controlled by an IBM XT-486 personal computer using Plasma 400 software. The spectrometer output was connected to Kipp \& Zonen Type BD 111 chart recorder (Environmental Monitors Ltd., UK). The ICP-OES operated at the conditions summarised in Table 1.

Table 1. Operating parameters for the ICP-OES

\begin{tabular}{lc}
\hline ICP Instrument- & \\
\hline Forward Power $(\mathrm{W})$ & 1350 \\
\hline ReflectedPower $(\mathrm{W})$ & 0 \\
\hline Aerosol gas flow rate $\left(\mathrm{I} \mathrm{min}^{-1}\right)$ & 0.8 \\
\hline Intermediate gas flow rate $\left(\mathrm{min}^{-1}\right)$ & 0.6 \\
\hline Outer gas flow rate $\left(\mathrm{I} \mathrm{min}^{-1}\right)$ & 12 \\
\hline Nebulizer & cross-flow \\
\hline Spray chamber & Ryton \\
\hline ICP date acquisition-emission wavelength & \\
\hline Element & Wavelength $(\mathrm{nm})$ \\
\hline $\mathrm{Co}$ & 238.892 \\
\hline $\mathrm{Ni}$ & 221.647 \\
\hline $\mathrm{Cu}$ & 324.754 \\
\hline $\mathrm{Zn}$ & 213.856 \\
\hline $\mathrm{Pb}$ & 220.353 \\
\hline $\mathrm{Mn}$ & 257.610 \\
\hline $\mathrm{Ch}$. & $0.05-2 \mathrm{~V} \mathrm{f.} \mathrm{d} \mathrm{d}, 1 \mathrm{~cm} \mathrm{~min}$ \\
\hline
\end{tabular}

The solid sediment samples were digested using a temperature-pressure controllable microwave oven (MDS 2100, CEM Corporation, USA). 


\subsection{Immobilisation of the 8-HQ onto the CPG}

$0.50 \mathrm{~g}$ of controlled porous glass (CPG) was boiled gently in $10 \mathrm{ml}$ of $5 \%(\mathrm{v} / \mathrm{v})$ nitric acid $\left(\mathrm{HNO}_{3}\right)$ solution for about 30 minutes. The CPG was washed with distilled water over a Büchner funnel until the filtrate attained $\mathrm{pH} 7$, then washed with water and dried in an oven at $95{ }^{\circ} \mathrm{C}$ for three hours. The dried beads were silanized with a $5 \%$ ( $p$-aminophenoxypropyl)trimethoxysilane solution prepared using anhydrous toluene for 4 hours at room temperature. The silanized beads were then filtered and washed with toluene and acetone before being dried at $110{ }^{\circ} \mathrm{C}$ in an oven overnight to ensure complete curing. This resulted in the formation of arylamine CPG. The cured arylamine CPG beads were left to cool at room temperature before being treated with $2 \%$ sodium nitrite in $2 \mathrm{M} \mathrm{HCl}$ at $0-4$ ${ }^{\circ} \mathrm{C}$ for 30 minutes. This reaction results in the formation of diazonium salt-CPG which was quickly filtered, washed with three $10 \mathrm{ml}$ portions of cold distilled water and added to $10 \mathrm{ml}$ of a $2 \%$ solution of 8-HQ in ethanol. Appearance of a deep red colour indicated the formation of the azo-coupled 8$\mathrm{HQ}$. This coupling reaction was carried out for 30 minutes, after which the CPG-immobilised 8-HQ was filtered and washed sequentially with ethanol, $0.1 \mathrm{M} \mathrm{HCl}$, and water. This material was then left to dry over a Büchner funnel for 2 hours and stored in a desiccator for subsequent use. The overall reaction is presented in figure 1.
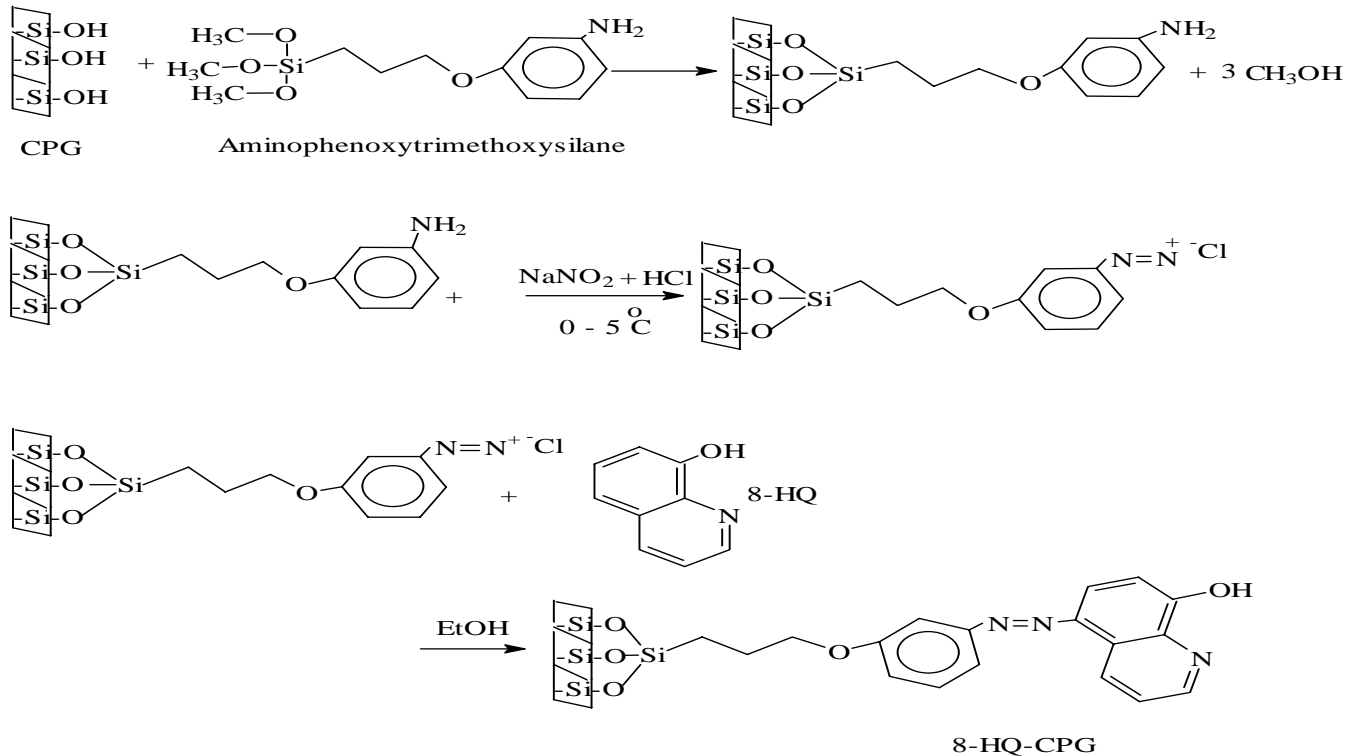

Figure 1. Reaction scheme for the covalent attachment of $\mathrm{HQ}$ onto silica (CPG)

\subsection{Flow injection manifold for the solid phase extraction}

The flow injection manifold for the solid phase extraction process is illustrated in Figure 2. It was designed to be simple, in order to be operated manually and to facilitate rapid processing for increasing the sampling frequency. A glass column $(3 \mathrm{~mm}$ i.d. and $25 \mathrm{~mm}$ length) (Omnifit, Cambridge, UK) was used in place of an injecting loop in a 6-port rotary valve (Omnifit). CPG-HQ material was packed into the column; at both ends $25 \mu \mathrm{m}$ pore size PTFE frits (Omnifit) were fixed to prevent material losses. A single four-channel peristaltic pump (Gilson Minipuls 3, Anachim, Luton, UK) was utilised to pump the sample and reagents throughout. The transport lines and mixing coils for sample and buffer delivery were made using $0.9 \mathrm{~mm}$ i.d. PTFE tubing and the eluent (nitric acid) delivered using $0.4 \mathrm{~mm}$ i.d. tubing. The pump speed was adjusted to deliver the eluent at a flow rate equal to the consumption rate of the nebulizer $\left(1.0 \mathrm{ml} \mathrm{min}^{-1}\right)$ and the column outlet could therefore be connected directly to the sample uptake device of the ICP-OES instrument.

At this optimum speed, the sampling flow rate was $4 \mathrm{ml} \mathrm{min}^{-1}$. Prior to operation, $2 \mathrm{M}$ nitric acid was pumped throughout the $\mathrm{FI}$ system for $15 \mathrm{~min}$ to remove any metal impurity and then the system was flushed with deionised water to remove residual acid. 


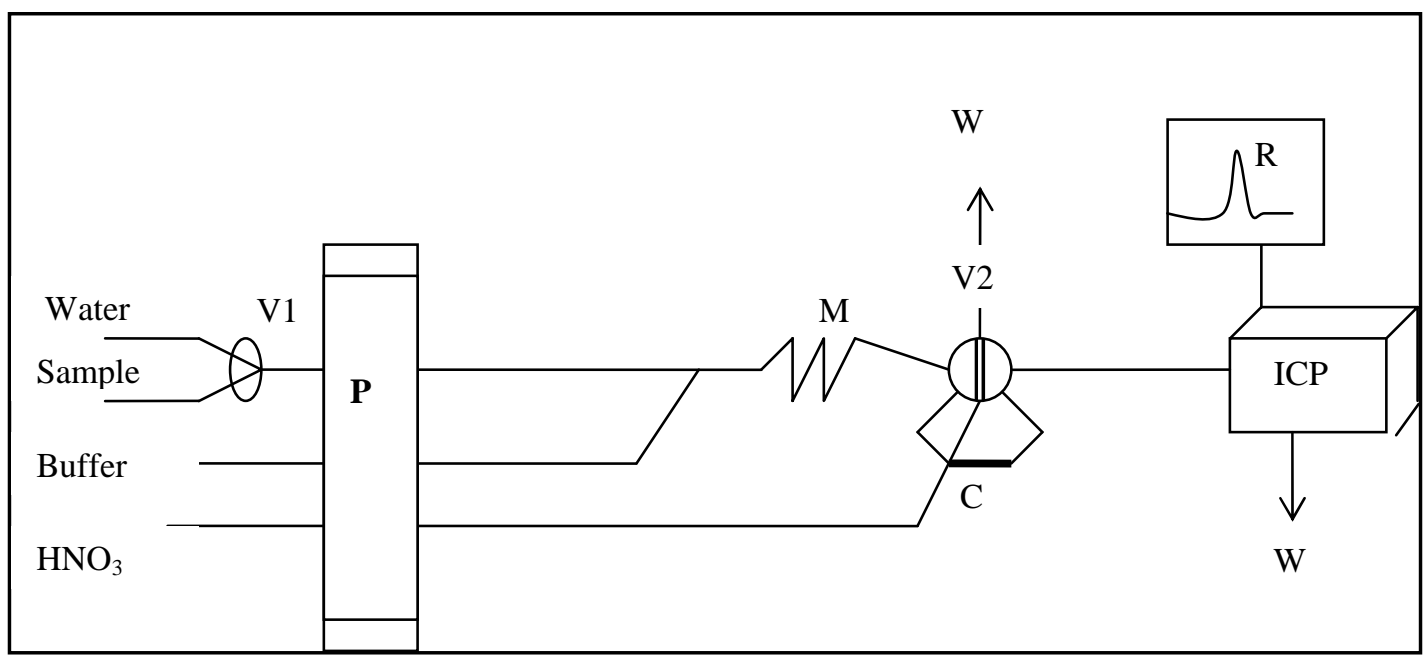

Figure 2. Flow Injection manifold; A SPE system for heavy metals coupled on-line with ICP-OES, where C; column, M; mixing coil, P; pump, V, selection valve, W, waste, R; chart Recorder

\subsection{Online solid phase extraction process}

The flow injection manifold described above interfaced with ICP-OES and utilised to perform online SPE according the following sequence. For conditioning, the first three way selection valve (V1) was switched to the water position and the second 6-port selection valve (V2) switched to the elution position to permit the water/buffer mixture to pass through the column while acid flow was maintained continuously to the ICP instrument. After column conditioning, the valve V1 was switched to permit standard / sample loading onto the column at $4 \mathrm{ml} \mathrm{min}^{-1}$ for the desired loading time. When reaching the duration of loading, V1 was switched back to a position that allowed water/buffer to flow in order to wash the column and transport lines from residual metals and weakly bound calcium and magnesium. By switching the V2 to elution position, the chelated trace metals were eluted off the columns with the eluent (nitric acid), countercurrent to the loading step. Opposite flow direction of loading and elution avoids problems due to the tendency of clogging, which would affect column performance, as well as maximizing preconcentration (Soksamiti et al., 1996). The column was prepared for the next run by its conditioning with buffer for $30 \mathrm{~s}$.

\subsection{Determination of exchange capacity}

The capacity of the immobilised $8-\mathrm{HQ}$ was determined for $\mathrm{Cu}$ and $\mathrm{Mn}$ was investigated using nitrogen micro-determination by elemental analysis (Kolstad et al., 1988) and by examining the Cu and Mn metal uptake in static and dynamic mode (Nelms et.al., 1995).

Resin stability and reusability

The stability of the prepared HQ-CPG materials was investigated in acid (0.50-4.0 $\left.\mathrm{M} \mathrm{HNO}_{3}\right)$. A portion of $0.5 \mathrm{~g}$ of resin was shaken with acid solutions of varying concentrations for $5 \mathrm{~h}$ and filtered. The solid was washed with distilled water until free from acid, dried at $120{ }^{\circ} \mathrm{C}$ in an oven and its sorption capacity was determined.

\subsection{Sediment digestion}

The solid sediments MESS-1 and GBW07309 were digested in microwave apparatus according to a validated protocol (Kowalewska et al., 1998). A portion of $0.50 \pm 0.02 \mathrm{~g}$ sediment powder was placed into a $250 \mathrm{ml}$ dry polytetraflouro-ethylene (PTFE) vessel, then a mixture of $4 \mathrm{ml} \mathrm{HF}, 3 \mathrm{ml}$ of $\mathrm{HCl}$ and $3 \mathrm{ml}$ of $\mathrm{HNO}_{3}$ was added. The vessel was covered loosely with a lid and left for 16 hours to allow organic gases to release. The microwave was then operated at a pressure of 120 psi and a temperature of $(170 \pm 5)^{\circ} \mathrm{C}$ for $25 \mathrm{~min}$. After venting and cooling, the digest was transferred into a 50 $\mathrm{ml}$ polyethylene centrifuging tube with $2 \% \mathrm{HNO}_{3}$, centrifuged using (Cenrtmic S-577 Lap-Plant, UK) at $300 \mathrm{~g}$ for $20 \mathrm{~min}$. The supernatant liquid was decanted into a $50 \mathrm{ml}$ volumetric flask, the volume was completed with $2 \% \mathrm{HNO}_{3}$, then, transferred immediately into a dry polyethylene container and kept at $4{ }^{\circ} \mathrm{C}$ prior to the analysis. This protocol was carried out for a batch of 5 vessels, including one 
as a blank. The sediment solution CRM-ES was used as supplied. The standard solutions for the calibration were prepared in $5 \%$ or $2 \%(\mathrm{v} / \mathrm{v}) \mathrm{HNO}_{3}$ to match the acidity of sample digests.

\section{RESULTS AND DISCUSSION}

\subsection{Immobilisation reaction}

A two step chemical transformation developed to immobilise 8-HQ onto controlled pore glass (CPG) is shown schematically in figure 2.2. In the first step, p-aminophenoxypropyltrimethoxysilane is employed to aminate the CPG surface by the usual silylation reaction in dry toluene. The second step in the sequence used to couple $\mathrm{HQ}$ to the aminophenoxypropyl-CPG involves diazotization coupling. The silylation reaction is believed to proceed throughout hydrolysis of the methoxy group of the silane, by the aid of surface adsorbed water, followed by condensation of a surface silanol with a silanol of the silylation agent (Vrancken 1995). Residual silanol groups of the silica beads can then be condensed by curing at $90-120^{\circ} \mathrm{C}$ (Leyden and Luttrell, 1975).

The use of aminophenoxypropyltriethoxysilane as a silylation agent allows the attachment of aromatic amine in one step and also provides a spacer arm of similar length as with the common procedure. Therefore the attachment of oxines by diazo coupling can be accomplished straightforwardly with no need to attach aromatic amine as usually required with conventional protocol. Aromatic amine attachment to the traditional silane, aminotriethoxysilane, attachment involves 24 hours condensation with nitrobenzoyl chloride in chloroform, followed by reduction of the nitro group to an amine with sodium dithionite. The reduction step itself has been reported to be problematic (Jezorek and Freiser 1979). The introduction of aromatic amine in the silylation step, however, shortens the time required to complete the conventional protocol (2-3 days) (Sugawara et al., 1974) and eliminates the limitations associated with the reduction step. This synthesis procedure enables an easily controllable immobilisation to be completed in less than a day in ambient temperature. In this work, the feasibility of this procedure was demonstrated by immobilising $8-\mathrm{HQ}$ onto CPG; however, it will be more appropriate for the attachment of oxines and similar reagents to silica surfaces within the porous structure of silica based monolithic materials (Asuhaimi, 2007). Moreover, it is green chemistry compatible, since no hazardous chemicals are used; therefore no harmful wastes are generated (Marshall and Mottola, 1983).

\subsection{Capacity study}

The nitrogen content can be taken as an indication of the surface converge and the success of the immobilisation. The capacity value based on nitrogen determination was found to be $0.267 \pm 0.029$ $\mathrm{mmol} \mathrm{g}{ }^{-1}$. Metals exchange capacity is a useful measure for cheating resins evaluation. Static and dynamic capacity values for Cu were $0.098 \pm 0.014$ and $0.106 \pm 0.011 \mathrm{mmol} \mathrm{g}^{-1}$, respectively, and for Mn were $0.091 \pm 0.016$ and $0.098 \pm 0.013 \mathrm{mmol} \mathrm{g}^{-1}$. The value obtained by nitrogen determination is reasonably consistent with that elicited by metal uptake methods and serves as evidence indicating that both metals form a 1:1 complex with the bound oxine.

There may be an argument as to the validity of the capacity values which are obtained by both the metal capacity and nitrogen methods. It has been reported that the free amine site in the silica immobilised $8-\mathrm{HQ}$ product would apparently react with $\mathrm{Cu}$ ion at higher $\mathrm{pH}$ and may thus result in higher capacity values than expected. To ensure that metals were extracted only by the immobilised $\mathrm{HQ}$, the aminophenoxypropyl-CPG (the product of the first step in the immobilisation process) blanks were run during metals capacity determination.

A similar situation may happen for the determination of nitrogen and carbon by elemental analysis. A former study showed that many $\mathrm{N}$ and $\mathrm{C}$ containing by-products, as impurities covalently bound to the silica surfaces, may be left when the conventional immobilisation protocol is employed to effect the attachment of oxines to silica materials. Subsequently, it will result in an erroneously high value of the bound reagent based on calculation of the measured carbon and nitrogen contents. However, in this short immobilisation procedure, the possibility of residual organic by-products being bound to the silica surface would be considerably reduced (Kolstad et.al., 1988). Capacity measurement by nitrogen determination on this resin can, therefore, be taken as a true capacity, taking into account the two nitrogen atoms involved in the diazo linkage of the reagent, which are expected not to contribute to the chelating process. 


\subsection{Optimising the SPE procedure}

\subsubsection{The effect of buffer $\mathrm{pH}$}

Since the solution $\mathrm{pH}$ affects the extent of complexation, which in turn determines the percentage of metal retained by the resin, the influence of the $\mathrm{pH}$ of $2 \mathrm{M}$ ammonium acetate buffer on the recovery of the selected metals was studied in the range from 3 to 9 . Standard metal solutions $\left(200 \mathrm{ng} \mathrm{ml}^{-1}\right.$ of each metal) were prepared in $2 \%$ nitric acid and buffered on-line using the FIA manifold. The recovery values for ions in study were evaluated from calibration curves obtained by direct injection of a series of standards prepared in $1.5 \mathrm{M}$ nitric acid. The results calculated as the average of three determinations are presented in Figure 3 . The effect of $\mathrm{pH}$ on sorption process may be explained as follow. Metal sorption starts when the $\mathrm{pH}$ rises to the range where most acidic ion exchange sites start to exchange hydronium ions $\left(\mathrm{H}^{+}\right)$for metals and the capacity reaches maximum value in the $\mathrm{pH}$ range where all the ion exchange sites take part in the reaction and the functional groups able to form chelate rings with metal cations. As the figure shows, all ions exhibited linear range with upward trends before reaching the maximum recovery, because the degree of dissociation increases and $\mathrm{H}^{+}$concentration in solution decrease. Nearly all metals studied reach maximum sorption around $\mathrm{pH}$ 5.5. At this $\mathrm{pH}$ value, the recovered value for the studied metals ranged from $100 \%$ for $\mathrm{Mn}$, and $\mathrm{Zn}$, and $78 \%$ for $\mathrm{Ni}$. Therefore, this $\mathrm{pH}$ value was considered for all the subsequent work.

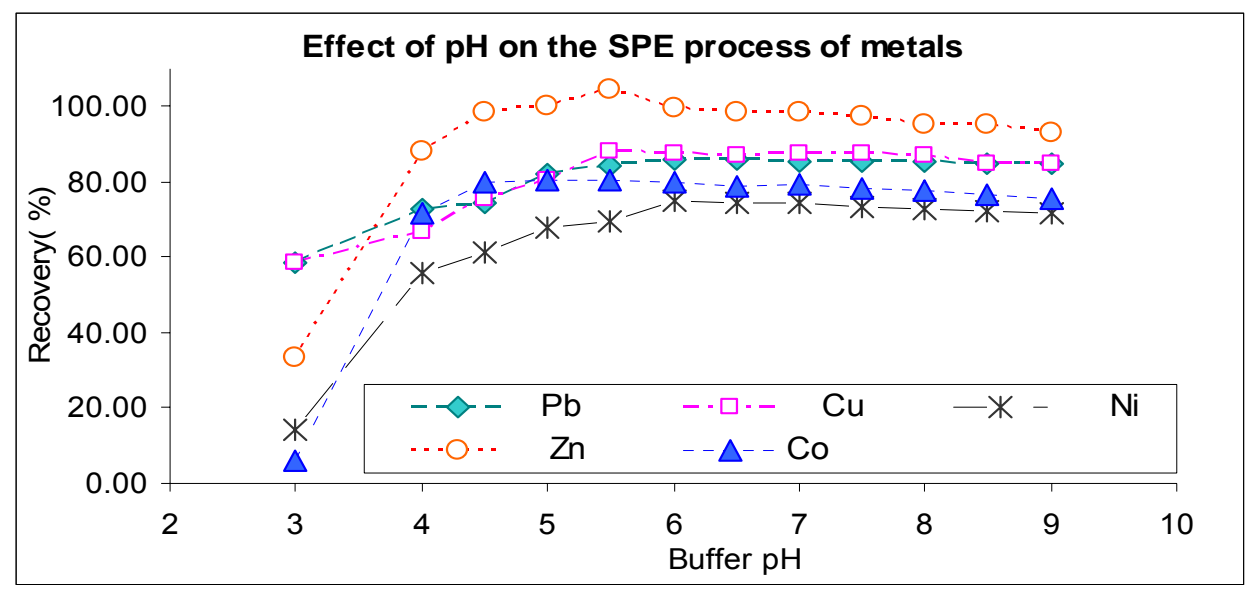

Figure 3. Effect of buffer $\mathrm{pH}$ on metals sorption

\subsubsection{The effect of eluent concentration}

The effect of nitric acid on metal desorption was evaluated by increasing the acid concentration from 0.1 to $2 \mathrm{M}$. The results were evaluated based on the recovery values and represented in Figure 4. Although some of the investigated metal ions could be eluted efficiently using low concentration of acid (e.g., $\mathrm{Cu}$ ), others required a concentration of $1.5 \mathrm{M}$ for quantitative recovery. The acid concentration required for each individual element increased as the formation constant of metalcomplex increased. In this study, acid concentration of $1.0 \mathrm{M}$ was considered to be sufficient to elute (recover) the maximum amount of all metals.

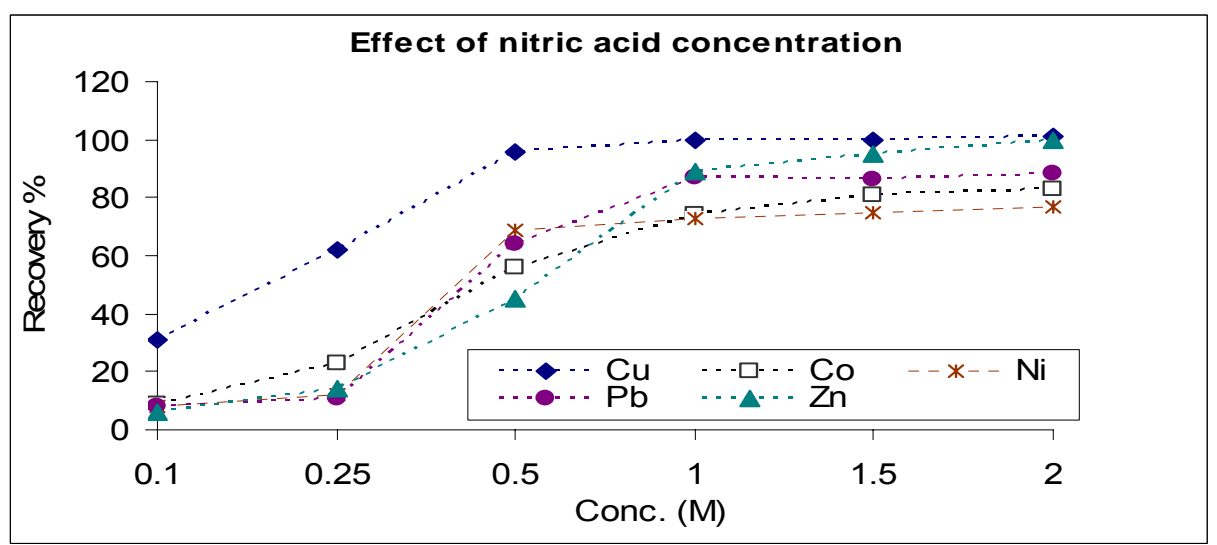

Figure 4. Effect of nitric acid eluent concentration on $200 \mathrm{ng} \mathrm{ml}^{-1}$ standards 


\subsubsection{Resin stability and reusability}

The sorption capacity for chelating resin treated with acid $(4 \mathrm{M})$ was found to be similar (variation $\leq 2.5 \%$ ) to that of the untreated one. Thus, the present resin can withstand $4.0 \mathrm{M} \mathrm{HNO}_{3}$, but a light orange coloration was immediately observed in the acid solution when the resin was placed in $5.0 \mathrm{M}$ acid solution. This could be attributed to the cleavage of the ether group of aminophenoxypropyl within the linker arm in highly concentrated acid. The sorption capacity of the resin was also reduced significantly after such treatment. Similarly, when the material was placed in solution of $\mathrm{pH}>9$, again an orange colour developed in the solution. The exchange capacity for the metal ions was determined after several loading and elution cycles. Insignificant decrease in the capacity $(2.41 \%)$ was observed after around 100 repeated cycles. Therefore, the chelating resin can be reused many times. On storing in dessicator for 10 months, the sorption capacity of 8-HQ-CPG does not change significantly.

\subsubsection{Method validation}

The digests of sediment samples were analysed using the FI manifold described in the experimental section. $2 \mathrm{M}$ ammonium acetate was used to buffer the standards and real sample on-line, before it passed the column. On-line buffering enables sample mixing and transportation to be carried out within a closed system and hence reduces the chance of contamination of analytes from the environment. The calibration standards were prepared in aqueous solution of $1 \%$ nitric acid, covering the dynamic range shown in the table 2 and used to determine the targeted metals in the real samples (sediment reference materials). Table 3 shows the concentration of the analysed metals in reference materials with the certified values. Apart from $\mathrm{Cu}$ and $\mathrm{Ni}$ ions in the solution (extract) of estuarine sediment, CRM-ES, all the analysed metals were quantified with satisfactory results. The low recovery of these ions could be ascribed to the presence of high level of competing matrix ions in this sample or due to the digestion procedure that being employed for the solid samples. However, the obtained values are still in agreement with the certified ones.

Table 2. Calibration parameters from the modified matrix

\begin{tabular}{lccccc}
\multicolumn{1}{c}{ Calibration Parameters } & $\mathrm{Co}$ & $\mathrm{Cu}$ & $\mathrm{Pb}$ & $\mathrm{Ni}$ & $\mathrm{Zn}$ \\
\hline $\begin{array}{l}\text { \% RSD at } 100 \mathrm{ng} \mathrm{ml}^{-1} \\
(\mathrm{n}=4)\end{array}$ & 1.35 & 2.11 & 1.75 & 1.21 & 1.14 \\
Correlation coefficient, $\mathrm{R}^{2}$ & 0.995 & 0.994 & 0.991 & 0996 & 0.986 \\
Sensitivity, $\mathrm{mV} \mathrm{ng}^{-1} \mathrm{ml}^{-1}$ & 0.16 & 0.42 & 3.21 & 0.31 & 0.46 \\
\hline
\end{tabular}

Table 3. Analysis of reference materials (in $\mu \mathrm{g} \mathrm{g}^{-1}$ ) (at $90 \%$ confidence level, $n=3$ )

\begin{tabular}{|c|c|c|c|c|c|c|}
\hline \multirow{3}{*}{ Metals } & \multicolumn{6}{|c|}{ Sample } \\
\hline & \multicolumn{2}{|c|}{ MESS-1 } & \multicolumn{2}{|c|}{ GBW07309 } & \multicolumn{2}{|c|}{ CRM-ES* } \\
\hline & $\begin{array}{l}\text { Found } \\
\text { (Recovery \%) }\end{array}$ & Certified & $\begin{array}{l}\text { Found } \\
\text { (Recovery \%) }\end{array}$ & Certified & $\begin{array}{l}\text { Found } \\
\text { (Recovery \%) }\end{array}$ & Certified \\
\hline Co & $\begin{array}{l}11.7 \pm 1.50 \\
(108 \%)\end{array}$ & $10.8 \pm 1.90$ & $\begin{array}{l}15.3 \pm 1.32 \\
(106 \%)\end{array}$ & 14.41 & $\begin{array}{l}0.11 \pm 0.03 \\
(110 \%)\end{array}$ & 0.10 \\
\hline $\mathrm{Cu}$ & $\begin{array}{l}22.62 \pm 3.62 \\
(90.1 \%)\end{array}$ & $25.1 \pm 3.80$ & $\begin{array}{l}30.7 \pm 2.41 \\
(95.6 \%)\end{array}$ & 32.10 & $\begin{array}{l}0.17 \pm 0.23 \\
(85.2 \%)\end{array}$ & 0.20 \\
\hline $\mathrm{Ni}$ & $\begin{array}{l}26.9 \pm 3.07 \\
(91.1 \%) \\
\end{array}$ & $29.5 \pm 2.40$ & $\begin{array}{l}29.3 \pm 2.94 \\
(90.7 \%) \\
\end{array}$ & 32.30 & $\begin{array}{l}0.22 \pm 0.09 \\
(73.2 \%) \\
\end{array}$ & 0.30 \\
\hline $\mathbf{P b}$ & $\begin{array}{l}31.58 \pm 5.61 \\
(92.9 \%)\end{array}$ & $34.0 \pm 6.10$ & $\begin{array}{l}21 \pm 1.54 \\
(91.3 \%)\end{array}$ & 23.00 & $\begin{array}{l}0.32 \pm 0.03 \\
(107 \%)\end{array}$ & 0.30 \\
\hline $\mathrm{Zn}$ & $\begin{array}{l}196.62 \pm 14.75 \\
(103 \%)\end{array}$ & $191.0 \pm 17.00$ & $\begin{array}{l}79 \pm 7.24 \\
(101 \%)\end{array}$ & 78.00 & $\begin{array}{l}1.71 \pm 0.34 \\
(114 \%)\end{array}$ & 1.5 \\
\hline
\end{tabular}




\section{CONCLUSION}

This work reports on a simple, rapid and green chemistry compatible chemical transformation for the covalent chemical attachment of oxines onto silica surfaces (e. i., controlled pore glass (CPG)). The procedure allows the synthesis of an 8-HQ-CPG resin possessing an identical chemical structure and chelating characteristics as that synthesis according to the common procedure. The use of aminoaraylsilane, aminophenoxypropyltrimethoxysilane, to activate silica makes, it easily achievable to attach oxines by straight diazotisation, thus the immobilisation process could be completed in a short time in comparison with traditional process, which is usually takes up to 3 days to be completed. Since only few synthetic steps are involved, this rapid process is an attractive for the immobilisation of oxines and similar reagents within the porous structure of monolithic silica materials, as the traditional method is impractical. For instance, since reagents are propelled through the microstructure, controlling of reaction conditions during prolonged steps (e.g., overnight heat) not possible as with batch methods.

The 8-HQ-CPG resin produced exhibited excellent performance as SPE materials for on-line sample preparation of trace metals prior to ICP-OES quantification. The validation study proved that the method is appropriate for matrix removal for the analysis of difficult environmental samples, such as sediments.

\section{REFERENCES}

Admas M.L. and Powell K.J., (2001), Flow injection method for iron fractionation by reaction with oxinederivatised Fractogel, Anal. Chim. Acta, 433, 289-297.

Anthemidis A.N., Zachariadis G.A. and. Stratis J.A., (2001), On-line solid phase extraction system using PTFE packed column for the flame atomic absorption spectrometric determination of copper in water samples, Talanta, 54, 935-942.

Bauman A.J., Weetal H.H. and Weliky N., (1967), Coupled ligand chromatography applications to trace element collection and characterization, Anal. Chem., 39, 932-936.

Csanay G., Naryanan P., Muller K., Wegscheider W. and Knapp G., (1989), Synthese verschiedener Oxincellulosen für spurenanalytische Anreicherungs-verfahren, Angew. Makromol. Chem., 170, 159172.

Dierssen, Balzer H.W. and Landing W.M., (2001), Simplified synthesis of an 8-hydroxyquinoline chelating resin and a study of trace metal profiles from Jellyfish Lake, Mar. Chem, 73, 173-192.

Dionex Corporation, (2003), Elimination of Iron and Aluminum Interferences in Sample Matrices by Ion Chromatography/Inductively Coupled Argon Plasma Emission Spectroscopy (IC/ICAP), Application Note, No 76, 1-7.

Fang Z., Guo T. and Welz B., (1991), Determination of cadmium, lead and copper in water samples by flame atomic-absorption spectrometry with preconcentration by flow-injection on-line sorbent extraction, Talanta, 38, 613-619.

Ghanthai S., Suwamart N. and Ruangviriyachai C., (2011), Solid-Phase Extraction with Diethyldithiocarbamate as Chelating Agent for Preconcentration and Trace Determination of Copper, Iron and Lead in Fruit Wine and Distilled Spirit by FlameAtomic Absorption Spectrometry, E.J. Chem., 8(3), 1280-1292.

Goswami A., Singh A.K. and Venkataramani B., (2003), 8-Hydroxyquinoline anchored to silica gel via new moderate size linker: synthesis and applications as a metal ion collector for their flame atomic absorption spectrometric determination, Talanta, 60, 1141-1154.

Hill J.M., (1973), Silica gel as an insoluble carrier for the preparation of selective chromatographic adsorbents: The preparation of 8-hydroxy-quinonline substituted silica gel for the chelation chromatography of some trace metals. J. Chromatogr. A., 76, 455-458.

Hiraide M., Iwasawa J. and Kawaguchi H., (1997), Collection of trace heavy metals complexed with ammonium pyrrolidinedithiocarbamate on surfactant-coated alumina sorbents, Talanta, 44, 231-237.

n V.K., Sait S.S., Shrivastav P. and Agrawal Y.K., (1997), Application of Chelate forming resin Amberlite XAD-2-o-vanillinthiosemicarbazone to the separation and preconcentration of copper(II), zinc(II) and lead(II), Talanta, 45, 397-404.

Jezorek J.R. and Freiser H., (1979), Metalion chelation chromatography on silicaimmobilized 8hydroxyquinoline, Anal. Chem., 51, 366-373.

Kolstad A.K., Chow P.T. and Canwell F.F., (1988), Spectrophotometric determination of the second acid dissociation constant of oxine bound to controlled pore glass, Anal, Chem., 60, 1565-1569. 
Kowalewaska Z., Bulska E. and Hulancki A., (1998), The effect of sample preparation on metal determination in soil by FAAS, Frensenius' J. Anal. Chem., 362, 125-129.

Lan C. and Yang M., (1994), Synthesis, properties, and applications of silicaimmobilized 8-quinolinol: Part 1. Characterization of silica-immobilized 8-quinolinol synthesized via a Mannich reaction, Anal. Chim. Acta, 287, 101-109.

Landing W.M., Haraldsson C. and Paxeus N., (1986), Vinylolymer agglomerate based transation metal cation -exchange cheating containing the 8-hydroxyquinoline functional group, Anal. Chem., 58, 30313035.

Leyden D.E. and Luttrell G.H., (1975), Preconcentration of trace metals using chelating groups immobilized via silylation, Anal. Chem., 47, 1612-1617.

Ma R., Van Mol W. and Adams F., (1994), Determination of cadmium, copper and lead in environmental samples: An evaluation of flow injection on-line sorbent extraction for flame atomic absorption spectrometry, Anal. Chim. Acta, 285, 33-43.

Ma R., Van Mol W. and Adams F., (1995), Flow injection sorbent extraction With dialkyldithiophosphates as chelating agent for the determination of zinc by flame atomic absorption spectrometry, Anal. Chim. Acta., 309, 395-403.

Marshall M.A. and Mottola H.A., (1983), Synthesis of silica-immobilized 8-quinolinol with (aminophenyl)trimethoxysilane, Anal. Chem., 55, 2089-2093.

Marshall M.A. and Mottola H.A., (1985), Performance studies under flow conditions of silica-immobilized 8-quinolinol and its application as a preconcentration tool in flow injection/atomic absorption determinations, Anal. Chem., 57, 729-733.

Mikula B. and Puzio B. (2007), Determination of trace metals by ICP-OES in plant materials after preconcentration of 1, 10-phenanthroline complexes on activated carbon, Talanta, 11, 136-40.

Nelms S.M., Greenway G.M. and. Hutton R.C, (1995), Application of multielement time-resolved analysis to a rapid on-line matrix separation system for inductively coupled plasma mass spectrometry, J. Anal. At. Spectrom., 10, 929-933.

Ozcan A.S., Gök O. and, Ozcan A., (2009), Adsorption of lead (II) ions onto 8-hydroxy quinolineimmobilized bentonite, J. Hazard. Mater., 161(1), 499- 509.

Parirish J.R., (1982), Chelating resins from 8-hydroxyquinoline, Anal. Chem., 54, 1890-1892.

Prado A.G.S., Arakaki L.N.H. and Airoldi C., (2002), Adsorption and separation of cations on silica gel chemically modified by homogeneous and heterogeneous routes with the ethylenimine anchored on thiol modified silica gel, Green Chem, 4, 42-46.

Prasada Rao T. and Mary Gladis J., (2001), Oxines as Preconcentration Agents in Inorganic Trace Analysis, Rev. Anal. Chem., 20, 145-159.

Prasada Rao T. and Mary Gladis J., (2002), Quinoline-8-ol and its derivatives as preconcentration Agents in flow injection analysis coupled to atomic and molecularspectrometric techniques, Anal. Sci., 18: 517-524.

Soksamiti P., Geckeis H. and Grudpan K., (1996), Determination of lead in soil samples by in-valve solidphase extraction-flow injection flame atomic absorption spectrometry, Analyst, 121, 1413-1417.

Soylak M., Karatepe A.U., Elci L., Doghan M., (2003), Column Preconcentration Separation and Atomic Absorption Spectrometric Determinations of Some Heavy Metals in Table Salt Samples Using Amberlite XAD-1180, Turk. J. Chem., 27, 235-242.

Sugawara K.F., Weetal H.H. and Schucker G.D., (1974), Preparation, properties and applications of 8hydroxyquinoline immobilized chelate, Anal. Chem., 46, 489-492.

Tertykh V.A., Yanishpolskii V.V. and Panova Y.O, (2000), Covalent Attachment of Some Phenol Derivatives to the Silica Surface by Use of Single-stage Aminomethylation, J. Therm. Anal. Calor., 62, 545-549.

Tian H., Chang X., Hu Z., Yang K., He Q., Zhang L. and Tu Z., (2010), Activated carbon modified with 4(8-hydroxyquinoline-azo)benzamidine for selective solid-phase extraction and preconcentration of trace lead from environmental samples, Microchimica acta, 171(3-4), 225-232.

Vernon F. and Nyo K.M, (1977), Synthesis optimization and the properties of 8-hydroxy-quinoline ionexchange resins, Anal. Chim. Acta, 93, 203-210.

Vernon F. and Eccles H., (1973), Chelating ion-exchangers containing 8-hydroxy quinoline as the functional group, Anal. Chim. Acta, 63, 403-414.

Vrancken K.C., Possemiers K., Van Der Voort P. and Vansant E.E., (1995), Surface modification of silica gels with aminoorganosilanes, Colloids, Surf. A., 98, 235-241. 
Wen B., Shan X-Q., and Xu S-G., (1999), Preconcentration of ultratrace rare earth elements in seawater with 8-hydroxyquinoline immobilized polyacrylo-nitrile hollow fiber membrane for determination by inductively coupled plasma mass spectrometry, Analyst, 124, 621-626.

Zheng W., Miao J., Lee F.S.C. and Xiaoru W.,( 2006), Synthesis of 8-hydroxyquinoline Bonded Silica (SHQ) and Its Application in Flow Injection-inductively Coupled Plasma Mass Spectrometry Analysis of Trace Metals in Seawater, Chin. J. Anal. Chem., 34(4), 459-463.

Zih-Perenyi K., Lasztivy A., Horath Z. and Levai A., (1998), Use of a new type of 8-hydroxyquinoline-5sulphonic acid cellulose (sulphoxine cellulose) for the preconcentration of trace metals from highly mineralised water prior their GFAAS determination, Talanta, 47, 673-679. 